\title{
East Asian Genome-wide association study derived loci in relation to type 2 diabetes in the Han Chinese population
}

\author{
Esma Jamaspishvili1四, Sijia Zhang1, Huixin Tong1', Yongjie Chen¹, Zhongyu Zhou², Lulu Sun', \\ Elena Kazakova' and Qiao Hong ${ }^{10}$
}

1Department of Endocrinology and Metabolism, The Second Affiliated Hospital, Harbin Medical University, Nangang District, Harbin, Heilongjiang, China; ${ }^{2}$ Epigenetic Department, Harbin Medical University, Nangang District, Harbin, Heilongjiang, China

\begin{abstract}
Meta-analysis of GWAS in East Asian populations had established 10 loci that were associated with type 2 diabetes. Eight of them were with genome-wide significance and two with a border line association. Since these data have not been studied in an independent Han Chinese population, we aimed to investigate the association of these susceptibility loci with type 2 diabetes in an independent Han Chinese population. We executed a casecontrol study in 2000 Chinese by the SNPscan method. Firstly, the repetitive sequences of 10 loci were assessed. Next, we investigated the association of 8 SNPs out of 10 with type 2 diabetes and constructed the GRS of those 8 SNPs. Finally, the relationship of the 8 loci and diabetes-related traits was analyzed. Based on the fact, that highly repetitive sequences were detected in 2 SNPs, we investigated the remaining 8 SNPs. With the exception of four SNPs (CMIP rs16955379, PEPD rs3786897, PSMD6 rs831571, ZFAND3 rs9470794), the other SNPs had the same direction of effect (odds ratio [OR] $>1.0$ ) as in the original reports, especially GLIS3 rs7041847 and KCNK16 rs1535500 were significantly associated with type 2 diabetes ( $r$ 1535500: $p=0.005, O R=1.224,95 \%$ Cl 1.062-1.409; rs7041847: $p=0.035$, OR=1.118, $95 \% \mathrm{Cl}$ $1.070-1.388)$. The GRS constructed from the 8 SNPs was significantly associated with type 2 diabetes in the Chinese population $(p=0.004, \mathrm{OR}=1.065,95 \% \mathrm{Cl}$ : $1.021-$ 1.111). Among the participants with $24 \leq B M l<28 \mathrm{~kg} / \mathrm{m}^{2}$ the 8 SNPs were significantly associated with type 2 diabetes $(p=0.040, \mathrm{OR}=1.079,95 \% \mathrm{Cl}: 1.003-1.160)$. In quantitative trait analyses, WWOX rs 17797882 was associated with decreased HOMA- $\beta$ and increased level of TG and HDL-Ch, while PEPD rs3786897 and MAEA rs6815464 were associated with decreased fasting plasma glucose, and KCNK16 rs1535500 has shown a significant association with increased T-Ch and PSMD6 rs831571 had a significant association with decreased HDL-Ch. In Conclusion, with high probability the 8 loci identified in the East Asian GWAS meta-analysis are associated with type 2 diabetes in the Han Chinese population.
\end{abstract}

Key words: China, GWAS, diabetes

Received: 18 June, 2018; revised: 13 April, 2019; accepted: 25 April, 2019; available on-line: 30 May, 2019

『e-mail: qiaoh0823@sina.com (QH); esmajama@yahoo.com (EJ) Acknowledgements of Financial Support: This study was funded by the National Natural Science Foundation of China (81172742 and 81473053), the Natural Science Foundation of Heilongjiang Province (ZD201220)

Abbreviations: GWAS, East Asian Genome-wide association study GRS, genetic risk score; SNP, single nucleotide polymorphism; HDL$\mathrm{C}$, high-density lipoprotein cholesterol; LDL-C, low-density lipoprotein cholesterol; BW, body weight; TCH, total cholesterol; HOMA-IR, homeostasis model assessment of insulin resistance; TG, triglycer- ides; DM, diabetes mellitus; IR, insulin resistance; T2DM, type 2 diabetes mellitus; WGAS, whole genome association study; ANTIGAD, anti glutamic acid decarboxylase; WHO, World Health Organization

\section{BACKGROUND}

Type 2 diabetes (T2D) is more prevalent in Asians than in Europeans (Sakai et al., 2013). The highest incidences of T2D (about $80 \%$ ) are seen in developing countries. The greatest increase in prevalence is present in low- and middle-income countries, including Asia, where most cases will be found by 2030 . The estimated prevalence of diabetes among a representative sample of Chinese adults was at $11.6 \%$ and prevalence of pre-diabetes was at $50.1 \%$. Projections based on sample weighting suggest that this may represent up to 113.9 million Chinese adults with diabetes and 493.4 million with pre-diabetes. The prevalence of diabetes has increased significantly in recent decades and is now reaching epidemic proportions in China ( $\mathrm{Xu}$ et al., 2013). These findings indicate the importance of diabetes as a public health problem in China. Type 2 diabetes mellitus (T2DM), which accounts for $80-90 \%$ of all diabetes cases, is characterized by complex traits and is caused by both genetic and environmental factors (O'Rahilly et al., 2005). The impact of powerful hereditary factors in the development of T2DM gave us the inspiration to seek susceptibility genes of T2DM.

Genome-wide association studies (GWAS) is an important method to find T2DM susceptibility genes, and genetic risk score (GRS) is considered to be a useful and tractable measure to evaluate the effect of multiple candidate loci of interest (Peterson et al., 2011). GRS is constructed by summing the number of risk alleles for multiple loci and it had a much stronger effect on disease susceptibility than individual single nucleotide polymorphisms (SNPs).

In 2012, Cho reported a meta-analysis of GWAS in East Asian population (Cho et al., 2012). 10 gene SNPs (FITM2-R3HDML-HNF4Ars6017317, GCCI-PAX4 rs6467136, GLIS3rs7041847, PSMD6rs831571, ZFAND3rs9470794, PEPD rs3786897, KCNK16rs1535500, CMIPrs16955379, MAEArs6815464 and WWOX rs17797882) were identified to be associated with T2DM. A replication study was performed for a Japanese population, where association of 9 susceptibility loci with T2DM has been evaluated (MAEA rs6815464 has been identified in the Japanese population) (Imamura et al., 2012). There is no difference between the results of the Japanese study and the Cho's report. However, there are different genetic backgrounds among the East Asian populations (Bao et al., 2012). Many studies of associa- 
tion between the susceptibility SNP genes and T2DM are inconsistent among different ethnic groups.

Thus, we investigated the association of 10 SNPs reported by Cho with T2DM in the Chinese population. In the study presented here, we carried out research for 1000 cases and 1000 controls by the SNP scan method. Firstly, we assessed the repetitive sequences of the 10 loci and found that repetitive sequences of FITM2-R3HDML-HNF4A rs6017317 and GCCI-PAX4 rs6467136 were very high in our blood samples. There was no further analysis of those two loci as the highly repetitive sequences affect the genotyping results. Next, association of the other 8 loci with T2DM was investigated in the Han Chinese population and the GRS of 8 loci was constructed. Finally, we analyzed the relationship between the 8 loci and T2DM related traits.

\section{MATERIALS AND METHODS}

Ethics Statements. All participants were informed and consented to the protocol of this study before enrolling. The protocol was reviewed and proved by the Ethics Committee of Harbin Medical University. DNA samples were obtained from the peripheral blood of each participant.

Participants and DNA Preparation. Han Chinese participants, 2000, were recruited from the Second Affiliated Hospital of Harbin Medical University, including 1000 T2DM patients from the Department of Endocrinology and 1000 controls from the Medical Examination Center. T2DM was diagnosed according to the World Health Organization (WHO) criteria: fasting glucose $\geq 7.0 \mathrm{mmol} / \mathrm{L}$, or OGTT $2 \mathrm{hPG} \geq 11.1 \mathrm{mmol} / \mathrm{L}$ (Alberti et al., 1998). Control group inclusion criteria were: no history of abnormal plasma glucose; no family history of diabetes; fasting glucose $<5.10 \mathrm{mmol} / \mathrm{L}$ and $\mathrm{HbA} 1 \mathrm{c}$ $<6.0 \%$. The T2DM group and control group were strat- ified into subgroups, including $\mathrm{BMI}<24,24 \leq \mathrm{BMI}<28$ and $\mathrm{BMI} \geq 28$ (Matthews et al., 1985).

Exclusion criteria for cases were: patients with other types of diabetes; individuals with over 6 months duration of T2DM or those were treated with insulin; patients with acute diabetic complications or taking any drug to influence plasma glucose; individuals with heart disease, liver dysfunction, malignancy, and other serious systemic disease.

Blood samples were drawn for biochemical measurements (fasting plasma glucose, fasting insulin, HbA1c, total cholesterol, triacylglycerol, HDL-cholesterol and LDL-cholesterol). All biochemical parameters were measured enzymatically with an auto-analyzer (Roche PPD Biochemistry Auto-analyzer, USA). Height, weight, and blood pressure were measured accordingly. BMI was calculated as weight $\left(\mathrm{kg} /\right.$ height $\left.^{2} \times \mathrm{m}^{2}\right)$; HOMA-IR and HOMA- $\beta$, as measures of insulin resistance and $\beta$-cell function respectively, HOMA-IR=Fasting Insulin $(\mathrm{mU} /$ 1) $\times$ Fasting glucose $(\mathrm{mmol} / \mathrm{l}) / 22.5$ (Matthews et al., 1985), HOMA $-\beta=$ Fasting Insulin $(\mathrm{mU} / \mathrm{l}) \times 20 /($ Fasting glucose - 3.5) $\mathrm{mmol} / \mathrm{l}$ (Wallace et al., 2004).

Single nucleotide polymorphism (SNP) Genotyping. Genomic DNA was extracted from peripheral blood leukocytes. At first, the repetitive sequences of 10 SNPs were assessed. FITM2-R3HDML-HNF4A rs6017317 and GCCI-PAX4 rs6467136 were identified highly repetitive sequence, so we investigated other 8 SNPs in the present study.

Eight selected SNPs were genotyped by a custom-bydesign 48-Plex SNPscan TM Kit (Cat\#:G0104; Genesky Biotechnologies Inc., Shanghai, China). This kit was developed according to the patented SNP genotyping technology by Genesky Biotechnologies Inc., which was based on double ligation and multiplex fluorescence PCR (Chen et al., 2011). In order to validate the genotyping accuracy using SNPscan ${ }^{\mathrm{TM}} \mathrm{Kit}, 5 \%$ of duplicate samples were analyzed by single nucleotide extension using the

Table 1. Clinical and Biochemical Characteristics of the Study population.

\begin{tabular}{|c|c|c|c|}
\hline & Type 2 diabetes & Control & $p$ \\
\hline & $N=1000$ & $\mathrm{~N}=1000$ & \\
\hline SEX(male/female) & $612 / 388$ & $587 / 413$ & $0.232 \mathrm{~b}$ \\
\hline Age (year)a & $47 \pm 18$ & $42 \pm 19$ & $<0.0001$ \\
\hline BMI $\left(\mathrm{kg} / \mathrm{m}^{2}\right)^{\mathrm{a}}$ & $26.67 \pm 7.02$ & $23.14 \pm 4.80$ & $<0.0001$ \\
\hline $\mathrm{SBP}(\mathrm{mmHg})^{\mathrm{a}}$ & $130 \pm 20$ & $120 \pm 20$ & $<0.0001$ \\
\hline DBP $(\mathrm{mmHg}) \mathrm{a}$ & $80 \pm 10$ & $80 \pm 14$ & $<0.0001$ \\
\hline $\mathrm{T}-\mathrm{CH}(\mathrm{mmol} / \mathrm{L})^{\mathrm{a}}$ & $4.94 \pm 1.56$ & $4.78 \pm 1.28$ & 0.0156 \\
\hline $\mathrm{TG}(\mathrm{mmol} / \mathrm{L})^{\mathrm{a}}$ & $1.72 \pm 1.57$ & $1.17 \pm 0.94$ & $<0.0001$ \\
\hline $\mathrm{HDL}-\mathrm{CH}(\mathrm{mmol} / \mathrm{L})^{\mathrm{a}}$ & $1.17 \pm 0.36$ & $1.43 \pm 0.47$ & $<0.0001$ \\
\hline LDL-CH (mmol/L)a & $2.86 \pm 1.25$ & $2.90 \pm 1.06$ & 0.7723 \\
\hline $\mathrm{HbA1c}(\%)^{\mathrm{a}}$ & $9.15 \pm 3.7$ & $5.2 \pm 0.7$ & $<0.0001$ \\
\hline FPG $(\mathrm{mmol} / \mathrm{L})^{\mathrm{a}}$ & $9.505 \pm 5.08$ & $4.97 \pm 0.31$ & $<0.0001$ \\
\hline HOMA-IR & $4.81 \pm 4.72$ & $1.51 \pm 1.17$ & $<0.0001$ \\
\hline HOMA- $\beta^{a}$ & $38.76 \pm 47.51$ & $104.84 \pm 78.74$ & $<0.0001$ \\
\hline
\end{tabular}

aData are mean \pm S.D.; ${ }^{b}$ Chi-square test; $\mathrm{BMI}$, body mass index; SBP, systolic blood pressure; DBP, diastolic blood pressure; T-CH, total cholesterol; TG, triacylglycerol; HDL-CH, HDL-cholesterol; LDL-CH, LDL-cholesterol; HbA1c, Glycated hemoglobin; FPG, fasting plasma glucose; HOMA-IR, homeostasis model assessment of insulin resistance; HOMA- $\beta$, HOMA of $\beta$ cell function 
Table 2. Genotype distributions of 8 SNPs in the case and control groups.

\begin{tabular}{|c|c|c|c|c|c|c|}
\hline \multirow[t]{2}{*}{ SNP } & \multirow[t]{2}{*}{ Gene } & \multirow[t]{2}{*}{ Allele ${ }^{a}$} & \multicolumn{2}{|c|}{ Allele 11/12/22 } & \multicolumn{2}{|c|}{$p$ for HWE test } \\
\hline & & & T2DM & Control & T2DM & Control \\
\hline rs1535500 & KCNK16 & $\mathrm{G} / \mathrm{T}$ & $284 / 488 / 224$ & $317 / 468 / 190$ & 0.6023 & 0.4644 \\
\hline rs16955379 & CMIP & $\mathrm{C} / \mathrm{T}$ & $556 / 393 / 47$ & $569 / 363 / 42$ & 0.0316 & 0.0924 \\
\hline rs17797882 & WWOX & $\mathbf{T} / \mathrm{C}$ & $600 / 344 / 52$ & $568 / 363 / 45$ & 0.7681 & 0.1743 \\
\hline rs3786897 & PEPD & $\mathbf{A} / \mathrm{G}$ & $276 / 484 / 234$ & $261 / 497 / 215$ & 0.4415 & 0.4565 \\
\hline rs6815464 & MAEA & $\mathrm{C} / \mathrm{G}$ & $365 / 485 / 46$ & $337 / 451 / 188$ & 0.4607 & 0.0930 \\
\hline rs7041847 & GLIS3 & G/A & $243 / 461 / 292$ & $182 / 506 / 286$ & 0.0230 & 0.1115 \\
\hline rs831571 & PSMD6 & $\mathrm{C} / \mathrm{T}$ & $420 / 442 / 134$ & $432 / 427 / 117$ & 0.3022 & 0.4675 \\
\hline rs9470794 & ZFAND3 & $\mathrm{C} / \mathrm{T}$ & $83 / 404 / 508$ & 93/400/482 & 0.8321 & 0.4508 \\
\hline
\end{tabular}

aThe reported risk allele is indicated in bold; HWE: Hardy-Weinberg equilibrium

Multiplex SNaPshot Kit (Applied Biosystems Inc., Foster City, CA, USA). The success rates of the assay were $>98 \%$ for each SNP, and the concordance rates in the duplicate samples were $\geq 99 \%$.

Statistical Analysis. The Hardy-Weinberg equilibrium test was performed in the case and control group respectively. The genotypes were scored using an additive model $(0,1$, and 2 for homozygous for the non-effect allele, heterozygous, and homozygous for the effect allele, respectively). We calculated a GRS by counting the number of risk alleles of the 8 SNPs in each individual. Association of the GRS or each SNP with T2DM was evaluated by a logistic regression analysis with or without adjustment for age, sex, and BMI. Association of the GRS or each SNP with quantitative traits, including FPG, HbA1c, HOMA- $\beta$, HOMA-IR, TCH, TG, HDL-ch and LDL-ch was evaluated by a multiple linear regression analysis. The values of these traits in the present Chinese population showed a skewed distribution; therefore, we used the log-transformed values for the analyses.

Statistical analyses were performed using SPSS 17.0. A $p$ value $<0.05$ was considered significant.

\section{RESULTS}

Clinical characteristics of the participants are shown in Table 1. The age, BMI, SBP, DBP, TCH, TG, FPG, HbA1c, HOMA-IR in the T2DM cases were significantly higher than those in the controls. The HDL-ch and HOMA- $\beta$ in the T2DM cases were significantly lower than those in the controls.

The genotype distributions for all 8 SNPs did not deviate from HWE proportions $(p>0.05)$, except rs16955379 and rs7041847 in the T2DM cases $(\mathrm{p}=0.0316$ and $\mathrm{p}=0.0230$, respectively, Table 2).

Table 3. Association of 8 SNPs with T2DM

\begin{tabular}{|c|c|c|c|c|c|c|c|}
\hline \multirow[t]{2}{*}{ Gene } & \multirow[t]{2}{*}{ SNP } & \multirow[t]{2}{*}{$\mathrm{RA}^{\mathrm{a}}$} & \multirow{2}{*}{$\begin{array}{l}\mathrm{RAFb}^{\mathrm{b}} \\
\text { case/control }\end{array}$} & \multicolumn{2}{|c|}{ Unadjusted } & \multicolumn{2}{|c|}{ Adjustedc } \\
\hline & & & & $P$ value & $\mathrm{OR}(95 \% \mathrm{Cl})$ & $P$ value & $\mathrm{OR}(95 \% \mathrm{Cl})$ \\
\hline KCNK16 & rs1535500 & $\mathrm{T}$ & $0.470 / 0.435$ & 0.027 & $1.152(1.016-1.306)$ & 0.005 & $1.224(1.062-1.409)$ \\
\hline CMIP & rs16955379 & $C$ & $0.756 / 0.771$ & 0.268 & $0.920(0.795-1.066)$ & 0.226 & $0.903(0.765-1.065)$ \\
\hline WWOX & rs17797882 & $\mathrm{T}$ & $0.245 / 0.230$ & 0.592 & $1.042(0.898-1.208)$ & 0.541 & $1.054(0.891-1.247)$ \\
\hline PEPD & rs3786897 & $A$ & $0.521 / 0.522$ & 0.875 & $0.990(0.874-1.12)$ & 0.653 & $0.968(0.841-1.115)$ \\
\hline MAEA & rs6815464 & $\mathrm{C}$ & $0.610 / 0.577$ & 0.032 & $1.149(1.012-1.305)$ & 0.104 & $1.127(0.976-1.300)$ \\
\hline GLIS3 & rs7041847 & $A$ & $0.475 / 0.447$ & 0.070 & $1.123(0.991-1.273)$ & 0.035 & $1.118(1.070-1.388)$ \\
\hline PSMD6 & rs831571 & $\mathrm{C}$ & $0.644 / 0.661$ & 0.241 & $0.924(0.811-1.054)$ & 0.291 & $0.923(0.797-1.070)$ \\
\hline ZFAND3 & rs9470794 & $C$ & $0.286 / 0.302$ & 0.332 & $0.934(0.815-1.072)$ & 0.215 & $0.906(0.775-1.059)$ \\
\hline $\mathrm{GRS}^{\mathrm{d}}$ & & & & 0.006 & $1.061(1.017-1.106)$ & 0.004 & $1.065(1.021-1.111)$ \\
\hline
\end{tabular}

The results of logistic regression analyses are shown. aThe risk allele reported in the previous report. bRisk allele frequency. cAdjusted for age, sex and log-transformed BMI. dThe genetic risk score (GRS) was calculated according to the number of risk alleles by counting the 8 East Asian genome-wide association study derived SNPs. 
Table 4. Association of 8 SNPs with T2DM in the Chinese population stratified by BMI.

\begin{tabular}{|c|c|c|c|c|c|c|c|}
\hline \multirow{2}{*}{ SNP } & \multirow{2}{*}{ Gene } & \multirow{2}{*}{ Risk Allelea } & \multirow{2}{*}{ Subjects } & \multicolumn{2}{|c|}{ Unadjusted } & \multicolumn{2}{|c|}{ Adjusted $^{\mathrm{b}}$} \\
\hline & & & & $p$ value & OR $(95 \% \mathrm{Cl})$ & $p$ value & OR $(95 \% \mathrm{Cl})$ \\
\hline \multirow[t]{3}{*}{ rs1535500 } & KCNK16 & $\mathrm{T}$ & $\mathrm{BMl}<24$ & 0.001 & $1.474(1.193-1.822)$ & 0.001 & $1.481(1.194-1.838)$ \\
\hline & & & $24 \mathrm{~B} \leq \mathrm{Ml}<28$ & 0.085 & $1.208(0.974-1.498)$ & 0.078 & $1.218(0.978-1.517)$ \\
\hline & & & $\mathrm{BMI} \geq 28$ & 0.272 & $0.825(0.584-1.164)$ & 0.242 & $0.814(0.576-1.150)$ \\
\hline \multirow[t]{3}{*}{ rs16955379 } & CMIP & $\mathrm{C}$ & $\mathrm{BMI}<24$ & 0.971 & $1.005(0.780-1.294)$ & 0.973 & $0.996(0.770-1.287)$ \\
\hline & & & $24 \leq \mathrm{BMI}<28$ & 0.652 & $0.944(0.734-1.214)$ & 0.496 & $0.915(0.708-1.182)$ \\
\hline & & & $\mathrm{BMI} \geq 28$ & 0.716 & $0.929(0.624-1.383)$ & 0.650 & $0.912(0.611-1.360)$ \\
\hline \multirow[t]{3}{*}{ rs17797882 } & WWOX & $\mathrm{T}$ & $\mathrm{BMl}<24$ & 0.657 & $1.059(0.822-1.366)$ & 0.727 & $1.047(0.809-1.355)$ \\
\hline & & & $24 \leq \mathrm{BMl}<28$ & 0.241 & $1.165(0.903-1.502)$ & 0.370 & $1.126(0.869-1.460)$ \\
\hline & & & $\mathrm{BMI} \geq 28$ & 0.503 & $0.867(0.507-1.316)$ & 0.453 & $0.852(0.560-1.295)$ \\
\hline \multirow[t]{3}{*}{ rs3786897 } & PEPD & $A$ & $\mathrm{BMl}<24$ & 0.889 & $0.985(0.797-1.218)$ & 0.789 & $0.971(0.783-1.205)$ \\
\hline & & & $24 \leq \mathrm{BMI}<28$ & 0.816 & $1.026(0.828-1.271)$ & 0.758 & $1.035(0.832-1.288)$ \\
\hline & & & $\mathrm{BMI} \geq 28$ & 0.779 & $1.050(0.745-1.480)$ & 0.776 & $1.051(0.745-1.483)$ \\
\hline \multirow[t]{3}{*}{ rs6815464 } & MAEA & $\mathrm{C}$ & $\mathrm{BMI}<24$ & 0.079 & $1.213(0.978-1.505)$ & 0.060 & $1.234(0.991-1.536)$ \\
\hline & & & $24 \leq \mathrm{BMl}<28$ & 0.592 & $1.061(0.853-1.320)$ & 0.619 & $1.058(0.847-1.322)$ \\
\hline & & & $\mathrm{BMI} \geq 28$ & 0.712 & $1.068(0.753-1.516)$ & 0.693 & $1.073(0.756-1.524)$ \\
\hline \multirow[t]{3}{*}{ rs7041847 } & GLIS3 & $A$ & $\mathrm{BMI}<24$ & 0.891 & $0.985(0.797-1.218)$ & 0.955 & $1.006(0.811-1.249)$ \\
\hline & & & $24 \leq \mathrm{BMI}<28$ & 0.041 & $1.251(1.009-1.551)$ & 0.080 & $1.216(0.977-1.515)$ \\
\hline & & & $\mathrm{BMI} \geq 28$ & 0.385 & $1.166(0.825-1.647)$ & 0.347 & $1.181(0.835-1.670)$ \\
\hline \multirow[t]{3}{*}{ rs831571 } & PSMD6 & $C$ & $\mathrm{BMI}<24$ & 0.025 & $0.778(0.625-0.969)$ & 0.044 & $0.796(0.637-0.994)$ \\
\hline & & & $24 \leq \mathrm{BMI}<28$ & 0.849 & $1.022(0.816-1.279)$ & 0.888 & $1.017(0.808-1.279)$ \\
\hline & & & $\mathrm{BMI} \geq 28$ & 0.573 & $1.108(0.776-1.581)$ & 0.563 & $1.111(0.778-1.588)$ \\
\hline \multirow[t]{3}{*}{ rs9470794 } & ZFAND3 & $\mathrm{C}$ & $\mathrm{BMl}<24$ & 0.245 & $0.871(0.689-1.100)$ & 0.309 & $0.884(0.697-1.121)$ \\
\hline & & & $24 \leq \mathrm{BMI}<28$ & 0.196 & $0.854(0.673-1.085)$ & 0.238 & $0.864(0.077-1.102)$ \\
\hline & & & $\mathrm{BMI} \geq 28$ & 0.545 & $1.124(0.771-1.638)$ & 0.527 & $1.130(0.774-1.649)$ \\
\hline \multirow[t]{3}{*}{ GRS c } & & & $\mathrm{BMI}<24$ & 0.302 & $1.036(0.968-1.109)$ & 0.237 & $1.043(0.973-1.118)$ \\
\hline & & & $24 \leq \mathrm{BMl}<28$ & 0.035 & 1.079 (1.005-1.159) & 0.040 & $1.079(1.003-1.160)$ \\
\hline & & & $\mathrm{BMI} \geq 28$ & 0.127 & $1.105(0.972-1.255)$ & 0.137 & $1.101(0.970-1.250)$ \\
\hline
\end{tabular}

Results of logistic regression analysis are shown. aRisk allele reported in the previous reports. bAdjusted for age and sex. cThe GRS was calculated according to the number of risk alleles of the 8 SNPs

The results of the association study for each SNP with T2DM in the present Chinese population are shown in Table 3. KCNK16 rs1535500, GLIS3 rs7041847, WWOX rs17797882 and MAEA rs6815464 showed the same direction of effect (odds ratio [OR] $>1.0$ ) as in the original reports (Sanada et al., 2012). KCNK16 rs1535500 and GLIS3 rs7041847 were associated with T2DM (rs1535500: $p=0.005, \mathrm{OR}=1.224,95 \%$ CI 1.062-1.409; 
Table 5. Association of 8 SNPs with quantitative traits related to glucose metabolism in controls.

\begin{tabular}{|c|c|c|c|c|c|c|c|c|c|c|}
\hline Gene & SNP & $\mathrm{RA}^{\mathrm{a}}$ & $\mathrm{FPG}^{\mathrm{b}}$ & & $\mathrm{HbA} 1 \mathrm{c}^{\mathrm{b}}$ & & HOMA-IR & & HOMA- $\beta^{\mathrm{b}}$ & \\
\hline & & & Effect(SE) & $p$ value & Effect(SE) & $p$ value & Effect(SE) & $p$ value & Effect(SE) & $p$ value \\
\hline KCNK16 & rs1535500 & $\mathbf{T}$ & $0.023(0.015)$ & 0.127 & $-0.004(0.021)$ & 0.852 & $0.022(0.040)$ & 0.584 & $8.521(10.137)$ & 0.401 \\
\hline CMIP & rs16955379 & C & $0.002(0.018)$ & 0.908 & $0.031(0.025)$ & 0.220 & $0.005(0.047)$ & 0.913 & $0.631(11.961)$ & 0.958 \\
\hline WWOX & rs17797882 & $\mathbf{T}$ & $-0.018(0.018)$ & 0.309 & $0.022(0.025)$ & 0.373 & $-0.005(0.047)$ & 0.918 & $-29.231(11.877)$ & 0.014 \\
\hline PEPD & rs3786897 & A & $-0.045(0.015)$ & 0.002 & $-0.017(0.021)$ & 0.412 & $0.011(0.040)$ & 0.787 & $9.463(0.982)$ & 0.343 \\
\hline MAEA & rs6815464 & C & $-0.030(0.015)$ & 0.042 & $0.004(0.021)$ & 0.841 & $-0.016(0.040)$ & 0.697 & $2.849(10.160)$ & 0.779 \\
\hline GLIS3 & rs7041847 & A & $0.013(0.015)$ & 0.368 & $-0.020(0.021)$ & 0.359 & $-0.029(0.040)$ & 0.462 & $-5.098(10.011)$ & 0.611 \\
\hline PSMD6 & rs831571 & C & $0.025(0.016)$ & 0.117 & $0.022(0.022)$ & 0.328 & $0.005(0.042)$ & 0.907 & $-4.651(10.610)$ & 0.661 \\
\hline ZFAND3 & rs9470794 & C & $0.025(0.016)$ & 0.115 & $-0.027(0.023)$ & 0.246 & $0.036(0.043)$ & 0.401 & $16.485(10.841)$ & 0.129 \\
\hline GRSc & & & $0.004(0.004)$ & 0.368 & $0.005(0.006)$ & 0.403 & $0.011(0.012)$ & 0.347 & $4.774(3.008)$ & 0.113 \\
\hline
\end{tabular}

The results of linear regression analysis after adjusting for age, sex and log-transformed BMI are presented. aThe risk allele for type 2 diabetes reported in the previous report. bValues are log-transformed before the analysis. 'The GRS was calculated according to the number of risk alleles of the 8 SNPs. HOMA-IR, homeostasis model assessment of insulin resistance; HOMA- $\beta$, HOMA of $\beta$ cell function; FPG, fasting plasma glucose; HbA1c, Glycated hemoglobin

Table 6. Association of 8 SNPs with quantitative traits related to lipid in controls.

\begin{tabular}{|c|c|c|c|c|c|c|c|c|c|c|}
\hline Gene & SNP & $\mathrm{RA}^{\mathrm{a}}$ & $\mathrm{T}-\mathrm{CH}^{\mathrm{b}}$ & & $\mathrm{TG}^{\mathrm{b}}$ & HDL-ch ${ }^{b}$ & & & LDL-chb & \\
\hline & & & Effect (SE) & $p$ value & Effect (SE) & $p$ value & Effect (SE) & $p$ value & Effect (SE) & $p$ value \\
\hline KCNK16 & rs1535500 & $\mathrm{T}$ & $0.114(0.047)$ & 0.016 & $0.064(0.041)$ & 0.117 & $0.006(0.015)$ & 0.711 & $0.058(0.039)$ & 0.142 \\
\hline CMIP & rs16955379 & C & $0.028(0.056)$ & 0.614 & $0.048(0.049)$ & 0.326 & $-0.014(0.018)$ & 0.427 & $0.030(0.046)$ & 0.523 \\
\hline WWOX & rs17797882 & $\mathrm{T}$ & $0.019(0.056)$ & 0.739 & $0.119(0.048)$ & 0.014 & $0.037(0.018)$ & 0.042 & $0.016(0.046)$ & 0.731 \\
\hline PEPD & rs3786897 & $A$ & $-0.035(0.042)$ & 0.442 & $0.013(0.041)$ & 0.753 & $-0.012(0.015)$ & 0.422 & $-0.014(0.038)$ & 0.711 \\
\hline MAEA & rs6815464 & $\mathrm{C}$ & $-0.009(0.048)$ & 0.858 & $-0.034(0.041)$ & 0.408 & $0.026(0.015)$ & 0.095 & $0.006(0.039)$ & 0.885 \\
\hline GLIS3 & rs7041847 & $A$ & $-0.066(0.046)$ & 0.153 & $0.015(0.041)$ & 0.712 & $-0.020(0.015)$ & 0.201 & $-0.047(0.038)$ & 0.216 \\
\hline PSMD6 & rs831571 & $\mathrm{C}$ & $0.049(0.050)$ & 0.326 & $0.062(0.043)$ & 0.151 & $-0.033(0.016)$ & 0.042 & $0.049(0.041)$ & 0.232 \\
\hline ZFAND3 & rs9470794 & C & $0.091(0.050)$ & 0.067 & $0.007(0.044)$ & 0.877 & $0.002(0.017)$ & 0.915 & $0.046(0.041)$ & 0.264 \\
\hline GRS c & & & $0.023(0.014)$ & 0.108 & $0.004(0.013)$ & 0.742 & $-0.002(0.005)$ & 0.729 & $0.017(0.012)$ & 0.162 \\
\hline
\end{tabular}

The results of linear regression analysis after adjusting for age, sex and log-transformed BMI are presented. aThe risk allele for type 2 diabetes reported in the previous report. bValues are log-transformed before the analysis. cThe GRS was calculated according to the number of risk alleles of the 8 SNPs. T-CH, total cholesterol; TG, triacylglycerol; HDL-CH, HDL-cholesterol; LDL-CH, LDL-cholesterol

rs7041847: $p=0.035, \mathrm{OR}=1.118,95 \%$ CI 1.070-1.388, adjusted for age, sex, and BMI). The remaining 6 SNPs were not associated with type 2 diabetes in the present study $(p \geq 0.05)$. GRS constructed from the 8 SNPs was significantly associated with T2DM $(p=0.006, \mathrm{OR}=1.06$,
95\% CI 1.017-1.106, unadjusted, $\mathrm{p}=0.004, \mathrm{OR}=1.065$, 95\% CI 1.021-1.111, adjusted for age, sex and BMI).

We analyzed the association of these SNPs with T2DM in the studied participants stratified by BMI. The International Association for the Study of Obesity (IASO), 


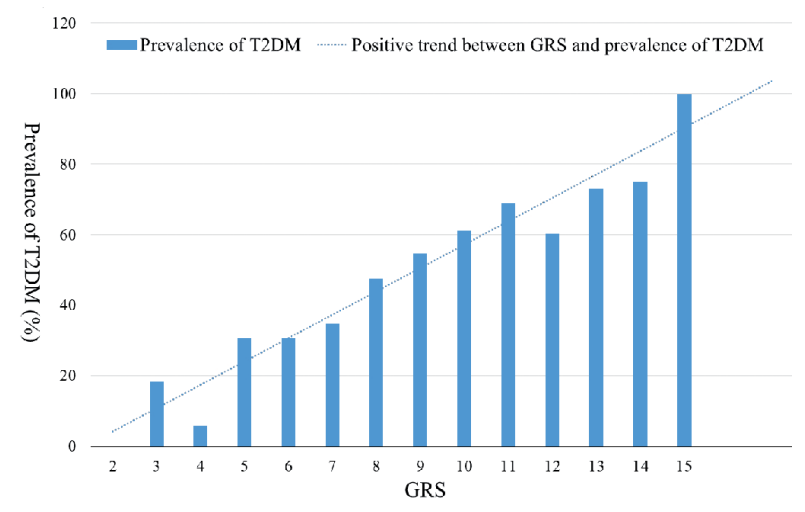

Figure 1. Trend between GRS and prevalence of T2D Bar graph on the figure shows the positive trend between GRS and prevalence of T2DM.

and the International Obesity Task Force (IOTF) defined overweight in Asians as having a $\mathrm{BMI} \geq 23 \mathrm{~kg} / \mathrm{m}^{2}$; obesity as $\mathrm{BMI} \geq 25 \mathrm{~kg} / \mathrm{m}^{2}$ (WHO Expert Consultation, 2004). China defines overweight as BMI of 24 or higher and obesity as BMI of 28 or higher (Low et al., 2009). The data are shown in Table 4. In the group with $\mathrm{BMI}<24$ $\mathrm{kg} / \mathrm{m}^{2}$, PSMD6 rs831571 and KCNK16 rs1535500 were associated with T2DM (rs831571: $p=0.044, \mathrm{OR}=0.796$, 95\% CI 0.637-0.994; rs1535500: $p=0.001, \quad \mathrm{OR}=1.481$, 95\% CI 1.194-1.838, adjusted for age and sex), while the 8 SNPs were significantly associated with T2DM $(p=0.040, \mathrm{OR}=1.079,95 \% \mathrm{CI}: 1.003-1.160$, adjusted for age and sex) in the group with $24 \leq \mathrm{BMI}<28 \mathrm{~kg} / \mathrm{m}^{2}$.

We examined the associations of these SNPs with quantitative traits related to glucose and lipid metabolism, such as HOMA-IR, HOMA- $\beta$, HbA1c, FPG and TCH, TG, HDL-ch, LDL-ch, in the control individuals (Table 5 and 6). WWOX rs17797882 was associated with a decreased HOMA- $\beta(\phi=0.014, \beta=-29.231$, se=11.961), an increased TG level $(p=0.014, \beta=0.119$, se $=0.048)$ and an increased HDL-Ch level $(\phi=0.042, \quad \beta=0.037, \quad s e=0.018)$. PEPD rs3786897 $(p=0.002, \quad \beta=-0.045$, se $=0.015)$ and MAEA rs6815464 ( $p=0.042, \beta=-0.030$, se $=0.015)$ were associated with a decreased fasting glucose. KCNK16 rs1535500 was associated with an increased T-Ch $(p=0.016, \beta=0.114$, $\mathrm{se}=0.047)$. PSMD6 rs831571 was associated with a decreased HDL-Ch $(p=0.042, \beta=-0.033$, se $=0.016)$.

\section{DISCUSSION}

In the study presented here, we evaluated the T2DM risk conferred by individual SNPs and the GRS constructed with the 8 SNPs. The accuracy of the genotyping was well validated, and the genotype distribution for each SNP in the controls did not deviate from HWE proportions. The technical factors were not likely to be a principal cause of the discrepancy between the study presented here and study and initial study.

In the single-SNPs analysis, GLIS3 rs7041847, KCNK16 rs1535500, MAEA rs6815464 and WWOX rs17797882 had shown the same direction of effect as in the original reports. KCNK16 rs1535500T and GLIS3 rs7041847A were found to be the risk alleles as they increased the risk of T2DM significantly. In the Japanese population, only KCNK16 rs1535500 was inconsistent with the original reports. Therefore, differences in genetic background, ethnicity and environmental factors among different East Asian populations (Bao et al., 2012) were likely to be the principal cause for the discrepancy between this Chinese study and the other population studies.

Construction of GRS is considered to be a useful and alternative approach to evaluate the effect of multiple candidate loci in an underpowered sample for singleSNPs analyses, like the present study. In the GRS analysis, we found that the GRS of 8 SNPs was significantly associated with T2DM in the Han Chinese population (Fig. 1). It indicates that the susceptibility to T2DM is conferred by a combined effect of the 8 SNPs. Therefore, we suggest that the 8 SNPs are important susceptibility loci for T2DM in the Han Chinese population. Because our results are not completely consistent with the other East Asian studies, the contribution of the 8 loci for susceptibility to T2DM in the Chinese population needs to be evaluated further in larger Chinese cohorts.

Obesity-associated insulin resistance is a major risk factor related to T2DM (Kramer et al., 2010). Evidence, that most genetic loci associated with susceptibility to T2DM were related to obesity has been found as well (Xi et al., 2012). Thus, we decided the participants should be stratified according to BMI. We found that the GRS constructed from the eight SNPs was significantly associated with $\mathrm{T} 2 \mathrm{DM}$ in the $24 \leq \mathrm{BMI}<28$ group. In the single-SNPs analysis, PSMD6 rs831571 and KCNK16 rs1535500 were associated with T2DM in the BMI $<24$ group. The results indicate that the association of the 8 SNPs with T2DM is more significant in overweight individuals. Based on the results, we could not strongly support an opinion about the connection between the 8 SNPs and obesity. The association of the 8 SNPs with T2DM was more significant in the Japanese population than in the Chinese population. The reason may be related to ethnic differences in BMI between the Japanese and the Chinese. Therefore the study of associations between T2DM-related SNPs and obesity is worthwhile to be carried out in different ethnic groups and areas.

The mechanism as to how these loci increased the susceptibility to T2DM is not clear yet. In the Japanese study, CMIP rs16955379 was associated with lower HOMA- $\beta$ and higher fasting glucose (Sakai et al., 2013). However, WWOX rs17797882 was related to lower HOMA- $\beta$ and increased TG in the Chinese population. KCNK16 rs1535500 increased the risk of total hypercholesterolemia T-Ch, and PSMD6 rs831571 was correlated to lower HDL-Ch. High plasma TG dyslipidemia can be considered as a predictor of T2DM as it decreases insulin sensibility and increases insulin resistance. Our study is a perfect example showing, the mentioned differences among the Asian populations, namely between the Japanese and Chinese. The 8 SNPs decreased insulin secretion in the Japanese study. However, besides reducing HOMA- $\beta$ the studied loci had affected the lipid metabolism and increased insulin resistance in the Chinese population.

The present study has several strengths. First, this study is the first to demonstrate that the 8 SNPs were associated with T2DM in the Chinese population. Second, all of the study subjects are Han Chinese who are genetically homogeneous. Third, as both - the insulin resistance and insulin insufficiency, have a major role in the development of T2DM, we comprehensively analyzed association of the 8 SNPs with all clinical parameters. Certainly, we cannot rule out the limitations of our study, because the present results were different from those previously reported. We couldn't analyze the effect of the size heterogeneity between Han Chinese population and East Asian population for the 8 SNPs analyzed in our study. However, it is obvious that the heterogeneity of different nations, variant susceptibility genes for disease according to different ethnicity and the 
different pathogenesis of T2DM in different populations are crucial, as they have a great effect and influence on the development and distribution of diabetes. Thus, replication studies should be conducted in the future that consider large samples and that are multi-regional and multi-national.

\section{CONCLUSIONS}

In conclusion, the 8 SNPs from East Asian Meta Analysis of GWAS were correlated to T2DM in the Han Chinese population. Further large scale association studies and functional studies should be done so that the found associations can be evaluated more thoroughly.

\section{Ethics approval and consent to participate}

This study was approved by the Ethics Committee of the Second Affiliated Hospital of Harbin Medical University, and written informed consent was obtained from all participants prior to inclusion. DNA samples were obtained from the peripheral blood of each participant.

\section{Consent for publication}

Not Applicable

\section{Availability of data and material}

The genotype data are presented in detail in the Tables. Data that do not pertain to individual patients will be freely available from the corresponding author on reasonable request. Any other information will be shared based on ethical clearance.

\section{Competing interests}

The authors declare that there is no competing interests regarding the publication of this paper.

\section{Authors' contributions}

The first two authors have contributed equally to this work. E.J. and S.Z. carried out genotyping, statistical analyses, and drafted the manuscript; H.T and Z.Z. made substantial contributions to analysis and interpretation of data; Y.C., L.S, and E.K, all designed the study as well as reviewed the manuscript and were involved in its critical revision before submission. Q.H. supervised the work, contributed the concept of research paper, revised the manuscript critically for important intellectual content and gave final approval of the version to be published. All authors have read and approved the final manuscript.

\section{Acknowledgements}

We gratefully acknowledge the numerous sample donors for making this work possible.

\section{REFERENCES}

Alberti KG, Zimmet PZ (1998) Definition, diagnosis and classification of diabetes mellitus and its complications. Part 1: diagnosis and classification of diabetes mellitus provisional report of a WHO consultation. Diabet Med 15: 539-553. https://doi.org/10.1002/ (SICI)1096-9136(199807)15:7<539::AID-DIA668>3.0.CO;2-S

Bao XY, Peng B, Yang MS (2012) Replication study of novel risk variants in six genes with type 2 diabetes and related quantitative traits in the Han Chinese lean individuals. Mol Biol Rep 39: 2447-2454. https://doi.org/10.1007/s11033-014-3022-Z

Chen X, Li S, Yang Y, Yang X, Liu Y, Liu Y, Hu W, Jin L, Wang $\mathrm{X}$ (2012) Genome-wide association study validation identifies novel loci for atherosclerotic cardiovascular disease. J Thromb Haemost 10: 1508-1514. https://doi.org/10.1371/journal.pone.0080374
Cho YS, Chen CH, Hu C, Long J, Ong RT, Sim X, Takeuchi F, Wu Y, Go MJ, Yamauchi T, Chang YC, Kwak SH, Ma RC, Yamamoto K, Adair LS, Aung T, Cai Q, Chang LC, Chen YT, Gao Y, Hu FB, Kim HL, Kim S, Kim YJ, Lee JJ, Lee NR, Li Y, Liu JJ, Lu W, Nakamura J, Nakashima E, Ng DP, Tay WT, Tsai FJ, Wong TY, Yokota M, Zheng W, Zhang R, Wang C, So WY, Ohnaka K, Ikegami H, Hara K, Cho YM, Cho NH, Chang TJ, Bao Y, Hedman AK, Morris AP, McCarthy MI, Takayanagi R, Park KS, Jia W, Chuang LM, Chan JC, Maeda S, Kadowaki T, Lee JY, Wu JY, Teo YY, Tai ES, Shu XO, Mohlke KL, Kato N, Han BG, Seielstad M (2012) Meta-analysis of genome-wide association studies identifies eight new loci for type 2 diabetes in east Asians. Nat Genet 44: 67-72. https://doi.org/10.1038/ng.1019

Han X, Luo Y, Zhang X, Lv C, Sun X, et al. (2013) Rs4074134 near BDNF gene is associated with type 2 diabetes mellitus in Chinese Han population independently of body mass index. PLoS One 8: e56898. https://doi.org/10.1371/journal.pone.0056898

Imamura M, Maeda S, Yamauchi T, Hara K, Yasuda K, Morizono T, Takahashi A, Horikoshi M, Nakamura M, Fujita H, Tsunoda T, Kubo M, Watada H, Maegawa H, Okada-Iwabu M, Iwabu M, Shojima N, Ohshige T, Omori S, Iwata M, Hirose H, Kaku K, Ito C, Tanaka Y, Tobe K, Kashiwagi A, Kawamori R, Kasuga M, Kamatani N, Nakamura Y, Kadowaki T (2012) A single-nucleotide polymorphism in ANK1 is associated with susceptibility to type 2 diabetes in Japanese populations. Hum Mol Genet 21: 3042-3049. https://doi.org/10.1093/hmg/dds113

Kramer H, Cao G, Dugas L, Luke A, Cooper R, Durazo-Arvizu R (2010) Increasing BMI and waist circumference and prevalence of obesity among adults with Type 2 diabetes: the National Health and Nutrition Examination Surveys. J Diabetes Complications 24: 368-374. https://doi.org/10.2147/DMSO.S50659

Li S, Zhongxin W (2005) Dyslipidemia, type 2 diabetes and metabolic syndrome. Med Rev 12: 1102-1104. https://doi.org/10.3949/ ccjm.84.s1.02

Low S, Chin MC, Ma S, Heng D, Deurenberg-Yap M (2009) Rationale for redefining obesity in Asians. Ann Acad Med Singapore 38: 66-69. https://doi.org/10.1177/1010539510390665

Matthews DR, Hosker JP, Rudenski AS, Naylor BA, Treacher DF, Turner RC (1985) Homeostasis model assessment: insulin resistance and beta-cell function from fasting plasma glucose and insulin concentrations in man. Diabetologia 28: 412-419. https://doi. org/10.1007/BF00280883

Mogre V, Salifu ZS, Abedandi R (2014) Prevalence, components and associated demographic and lifestyle factors of the metabolic syndrome in type 2 diabetes mellitus. J Diabetes Metab Disord 13: 80

O'Rahilly S, Barroso I, Wareham NJ (2005) Genetic factors in type 2 diabetes: the end of the beginning. Science 307: 370-373

Peterson RE, Maes HH, Holmans P, Sanders AR, Levinson DF, Shi J, Kendler KS, Gejman PV, Webb BT (2011) Genetic risk sum score comprised of common polygenic. Hum Genet 129: 221-230 https:// doi.org/10.1007/s00439-010-0917-1

Rabasseda X (2011) A report from the 47th European Association for the Study of Diabetes annual meeting. September 12-16, 2011 - Lisbon, Portugal. Drugs Today (Barc) 47: 923-934. https://doi. org/10.1358/dot.2011.47.1.1594347

Sakai K, Imamura M, Tanaka Y, Iwata M, Hirose H, Kaku K, Maegawa $H$, Watada $H$, Tobe $K$, Kashiwagi A, Kawamori R, Maeda S (2013) Replication study for the association of 9 East Asian GWAS-derived loci with susceptibility to type 2 diabetes in a Japanese population. PLoS One 8: e76317. https://doi.org/10.1371/journal.pone. 0126363

Sanada H, Yokokawa H, Yoneda M, Yatabe J, Sasaki YM, Williams SM, Felder RA, Jose PA (2012) High body mass index is an important risk factor for the development of type 2 diabetes. Intern Med 51: 1821-1826. https://doi.org/10.1186/1471-2261-6-10

Wallace TM, Levy JC, Matthews DR (2004) Use and abuse of HOMA modeling. Diabetes Care 27: 1487-1495. https://doi.org/10.2337/diacare.27.6.1487

WHO Expert Consultation (2004) Appropriate body mass index for Asian populations and its implications for policy and intervention strategies. Lancet 363: 157-163. https://doi.org/10.1016/S01406736(03)15268-3

Xi B, Takeuchi F, Chandak GR, Kato N, Pan HW, et al. (2012) Common polymorphism near the MC4R gene is associated with type 2 diabetes: data from a meta-analysis of 123,373 individuals. Diabetologia 55: 2660-2666. https://doi.org/10.1007/s00125-012-2655-5

Xu Y, Wang L, He J, Bi Y, Li M, Wang T, Wang L, Jiang Y, Dai M, Lu J, Xu M, Li Y, Hu N, Li J, Mi S, Chen CS, Li G, Mu Y, Zhao J, Kong L, Chen J, Lai S, Wang W, Zhao W, Ning G (2013) Prevalence and control of diabetes in Chinese adults. 2010 China Noncommunicable Disease Surveillance Group 4: 948-959. https:// doi.org/10.1001/jama.2013.168118

Ziying Z, Yaoming X (2003) Hypertriglyceridemia and type 2 diabetes. Chinese J Diabetes 02: 81-82 